Liquiritin from Glycirrhyza glabra L (Fabaceae) - A natural derived drug, as a potential inhibitor for SARS-CoV-2

Akash Vanzara ${ }^{1}$, Ravi Patel ${ }^{1}$, Amisha Patel ${ }^{2}$, Nimisha Patel ${ }^{1}$, Kapil Yadav ${ }^{1}$, Padamnabhi S. $\operatorname{Nagar}^{1} *$

${ }^{1}$ Department of Botany, Faculty of Science, The Maharaja Sayajirao University of Baroda, Vadodara-390002, Gujarat, India.

${ }^{2}$ P. G. Department of Biosciences, Sardar Patel University, Satellite Campus, Vadtal Road, Bakrol-388 315, Anand, Gujarat, India

*Corresponding author: $\underline{\text { dr.nagar@gmail.com }}$ 


\title{
Liquiritin from Glycirrhyza glabra L (Fabaceae) - A natural derived drug, as a potential inhibitor for SARS-CoV-2
}

\begin{abstract}
:
Novel Corona virus-2 (Covid-19) is spreading and causing major damage around the globe and constantly increasing daily. There is a prerequisite of expeditious development of safe and efficient drugs for such a contagious disease. In this regard, utilization of a computational approach with an aim to provide potential enzyme inhibitors derived from natural resources will give a providential therapy. The present study investigated one of the promising plants namely Glycyrrhiza glabra L. It has various medicinal properties viz. anti-inflammatory, anticancer, anti-demulcent, expectorant, etc. In-Silico Analysis of liquiritin against SARS-CoV-2 Mpro was carried out using Autodock 4.2.6 and results were compared with presently prescribed drugs i.e. dexamethasone, remdesivir, hydroxychloroquine, and azithromycin. The binding energy of liquiritin was found to be $-6.62 \mathrm{kcal} / \mathrm{mol}$. It shows presence of hydrogen bond, hydrophobic interaction and electrostatic interaction with six active residues THR26, GLY143, CYS145, HIS 164, GLU166, and GLN189. Comparative studies investigated that dexamethasone, remdesivir, hydroxychloroquine, and azithromycin have four (THR26, GLY143, CYS145, GLU166), three (CYS145, GLU166, GLN189), four (GLY143, CYS145, HIS 164, GLN189) and two (GLU166, GLN189) identical active residues, respectively. The present study recommended liquiritin as a potential candidate against SARS-CoV-2 as it is naturally derived and has tremendous traditional usage against various diseases. However, invitro and in-vivo studies are required to prove its efficacy.
\end{abstract}

Keyword: Liquiritin; SARS-COV-2; Dexamethasone; Hydroxychloroquine; Azithromycin; Remdesivir

\section{Introduction}

In the wake of COVID-19 outbreak, mankind sufferingwith high risk of safety and health issues all over world. It was began at the end of year 2019, and still continues to causing major backdrop to the world. It affects most to the health sector, wherein globally 17,512,049 active cases and 677,543 deaths recorded at the end of August-2020 (1). Presently there are certain drugs which prescribed by health expertise across world viz. remdesivir, hydroxychloroquine, dexomethasone, azithromycin. As per emergency protocol, first patient, 35 year old from Washington, affected with COVID19 showed improvement in pneumonia 
after 7 days of treatment with remdesivir (2). Seven critically ill patients were treated with much compassionate drug remdesivir in Seattle USA (3). In more extensive study, 10-day course of a drug remdesivir treatment by intravenous administration at the dose of $200 \mathrm{mg}$ on day 1 , followed by $100 \mathrm{mg}$ daily, $68 \%$ of patients with COVID-19 showed clinical improvement (4). Hydroxychloroquine is generally used to treat malaria, a lupus erythematosus, and rheumatoid arthritis. However, according to WHO, 2020b (5), drug does not reduce the death of hospitalized COVID-19 patients. As per preliminary study conducted by UK national clinical trial, dexamethasone would help critically ill patients, but patients on mechanical oxygen support, reduces mortality rate about one third where as patient who requires only oxygen, mortality rate was observed as one fifth (6). According to retrospective multicentre cohort study of patients in New York state, probability of death among the group of patients receiving combined treatment of hydroxychloroquine and azithromycin was $25.7 \%$ wherein with alone treatment of azithromycin was $10 \%$. Furthermore, in adjustment Cox proportional hazard models, patients neither receive combination of drug nor alone one, there were no significant difference in mortality (7).

Nature has always overwhelmed us with many new and unique bioactive compounds which possess potential activity against various disease and infection (8). Hence, there is prerequisite of scientific community to draw the diverse knowledge of traditional system (9). This pandemic disease is almost controlled in China, wherein traditional Chinese Medicine (TCM) has played a specific role which cannot be overlooked (10). According to reports, during peak of epidemic in China, over 3100 TCM workforce deployed to Hubei province and was officially included in Chinese guidelines diagnosis and treatment of COVID-19 which indicates the importance of traditional usage of natural medicine $(11,12)$. Glycyrrhiza glabra L. (Fabaceae) is widely used as in folk medicines for various diseases and infection (13) like leaves for wound treatments (14); root for diabetes and aphrodisiac; and stem for tuberculosis $(15,16)$. It has antimicrobial properties (17), antiplatelet aggregation effect (18) and is used as cough-relieving medicinalherb from ancient time (13). It shows inhibitory effect on inflammation-associated corneal neovascularization (19). Plant possesses several bioactive compounds such as flavonoids, isoflavonoids, stibenoids, saponin and coumarins. Wherein, constituents of flavonoids are liquirtin, liquiritgenin and neoliquiritin. In isoflavonoid active components include glabridin, glabrone, glyzarin and galbrene (20). Similarly, in stibenoids bioactive constituent is dihydrostilbenes (21). Furthermore, the active constituents in saponins are glycyrrhizin, liquiritic acid and glycerretol. Finally, in coumarins 
the active components are liqcoumarin and umbelliferone (20). Liquirtin is a flavanone glycoside that is liquiritigenin attached to a $\beta$-D-glycopyranosyl residue at $4^{\text {th }}$ position via glycoside linkage which considered as anticoronaviral and anti-inflammatory agent (22). With addition to that liquirtin have certain medicinal properties, such as antioxidant, antidepressant, neuroprotective, anti-inflammatory and also considered in therapy of heart disease $(23,24)$. Liquirtin is considered as safe and used for inhibitory activity against CoV-2 mimicking type I interferon, wherein it employed by transcriptional analysis of which it has significant potency to inhibit replication of COVID-19 in Vero E6 cells with $\mathrm{EC}_{50}$ of 2.39 $\mu \mathrm{M}$. While in toxicity experiment; when ICR mice were treated with $300 \mathrm{mg} / \mathrm{kg}$ dosage, no death was observed. Liquirtin also exists within licorice tablet $(0.2 \%$ by mass $)$ used in traditional Chinese medicine. Zhu et al., 2020 (25) and Rastogi et al., 2020 (9), reported the use of this compound in polyherbal formulation and exposed to asymptomatic patients (quarantined group), however there was no data available on in-vivo studies. In this context, the approach of present study was to investigate the efficacy and potency of liquirtin against SARS-CoV-2 by employinging In-silico analysis. The present study was analysed molecular based interaction of liquirtin in contrast with dexamethasone, remdesivir, hydroxychloroquine and azithromycin against 6LU7 protein crystallographic structure of SARS-CoV-2M $\mathrm{M}^{\text {pro }}$.

\section{Materials and Methodology}

\subsection{Virtual Screening}

\subsubsection{Proteins/Macromolecules}

Virtual screening was carried out using the crystallographic structure of SARS-CoV-2 $\mathrm{M}^{\text {pro }}$ along with an inhibitor N3 (26). The structure was downloaded from PDB (Protein Data Bank) with accession number 6LU 7 (Deposited: 26-01-2020; released: 05-02-2020).

\subsubsection{Drug and ligand download}

Three dimensional (3D) structures of drugs were retrieved using ZINC and PubChem database. Liquirtin (CID 503737), dexamethasone (CID 5743), remdesivir (CID 121304016), and hydroxychloroquine (CID 3652) were retrieved from PubChem database whereas azithromycin (ZINC 85537026) was downloaded from ZINC database in sdf format. Liquirtin was examined for Lipinski rules of 5 related to drug-likeness properties i.e. hydrogen bond acceptor should not exceed to 10 , hydrogen donors not more than 5, 
molecular weight should between 160 to $500 \mathrm{~g} / \mathrm{mol}, \operatorname{logP}$ should between -0.4 and 5.6 (27). SWISSADME prediction was used to analyse dug likeliness properties of liquiritn (28).

\subsubsection{Active site determination}

Biovia Discovery Studio 2020, UCSF Chimera (version 1.14) and previous studies on crystallographic structure of SARS-CoV-2 $\mathrm{M}^{\text {pro }}(26,29-31)$ were used to determine active sites of SARS-CoV-2 $\mathrm{M}^{\text {pro }}$. Docking results were evaluated by the analysis of grid box using the determined amino acids (PHE140, GLY143, CYS145, HIS163, HIS164, GLU166, GLN189 and THR190) present in active site of SARS-CoV-2 $\mathrm{M}^{\text {pro }}$.

\subsubsection{Molecular Docking}

Open Babel GUI 3.0 software was used to convert ligand into pdb format from sdf format. AutoDock Tools 1.5.6 was used to convert the structure of 6LU7 protein molecule and all ligand molecules to corresponding pdbqt format (32). AutoDock version 4.2.6 was utilised for optimization of protein by adding Kollman charges and polar hydrogen group; and removing water and other atoms. The grid box was set by arranging the grid coordinates $(\mathrm{X}$, $\mathrm{Y}$, and $\mathrm{Z}$ ) on the active site. Each docking run was accomplished four times using GA (genetic algorithm) parameters with 1,750,000 generations. The average affinity energy value was considered out of ten best docking hits. PyMol 2.3 was used to analyse the docking positions for confirmation of molecule interactions with the amino acids within the $\mathrm{M}^{\text {pro }}$ active site (33). Two dimensional (2D) maps of receptor-ligand interactions were generated using Discovery Studio Visualizer 2020.

\subsubsection{ADMET study}

The pkCSM- pharmacokinetics server was used for ADMET-Absorption Distribution Metabolism, Excretion and toxicity study (34). Open Babel GUI 3.0 software was used to convert sdf file of the ligands into SMILES (Simplified Molecule Input Line Entry Specification) format which were uploaded to pkCSM to calculate ADMET properties.

\section{Results}

\subsection{Lipinski/Pfizer rules}

Liquiritin was analysed for Lipinski/Pfizer rules and compared with dexamethasone, remdesivir, hydroxychloroquine and azithromycin (Table 1). A Plant derived drug liquiritin showed zero violation with nine hydrogen-bond acceptor; five hydrogen-bond donors and 
molecular weight of $418.39 \mathrm{~g} / \mathrm{mol}$. Moreover, lipophilicity $\mathrm{iLog} P_{\mathrm{O} / \mathrm{w}}$ was found to be 2.21 , In dexamethasone, drug showed zero violation for Lipinski rules; it possessed six hydrogenbond acceptor; three hydrogen-bond donors and molecular weight of $392.46 \mathrm{~g} / \mathrm{mol}$. The lipophilicity $\mathrm{iLog} P_{O / W}$ was obtained as 2.29. While in remdesivir, druglikeness properties was observed with two violations wherein number of hydrogen bond acceptor was twelve and molecular weight of drug was $602.58 \mathrm{~g} / \mathrm{mol}$, lipophilicity $\mathrm{iLog} P_{O / W}$ was obtained as 3.40. Similarly, in azithromycin druglikeness properties possessed two violations with fourteen hydrogen bond acceptor and molecular weight of $748.98 \mathrm{~g} / \mathrm{mol}$. In hydroxychloroquine, drug showed zero violation with three hydrogen-bond acceptor; two hydrogen-bond donors and molecular weight of $335.87 \mathrm{~g} / \mathrm{mol}$. 
Table 1. Pharmacokinetic study of Liquiritin, Dexomethasone, Remdesivir, Hydroxychloroquine and Azithromycin using Lipinski rules of five.

\begin{tabular}{|c|c|c|c|c|c|}
\hline \multirow[t]{2}{*}{ Sr. No. } & \multirow[t]{2}{*}{ Name of Compound } & \multirow[t]{2}{*}{ Structure } & \multirow[t]{2}{*}{ Molecular formula } & \multicolumn{2}{|l|}{ Lipinski rules of five } \\
\hline & & & & Properties & Values \\
\hline \multirow[t]{5}{*}{1} & \multirow[t]{5}{*}{ Liquiritin } & & \multirow[t]{5}{*}{$\mathrm{C}_{21} \mathrm{H}_{22} \mathrm{O}_{9}$} & Molecular weight $(<500 \mathrm{~g} / \mathrm{mol})$ & $418.4 \mathrm{~g} / \mathrm{mol}$ \\
\hline & & & & $\log \mathrm{P}(<5)$ & 2.21 \\
\hline & & & & H-Bond donor $(<5)$ & 5 \\
\hline & & & & H-Bond acceptor $(<10)$ & 9 \\
\hline & & & & Violation & 0 \\
\hline \multirow[t]{5}{*}{2} & \multirow[t]{5}{*}{ Dexamethasone } & & \multirow[t]{5}{*}{$\mathrm{C}_{22} \mathrm{H}_{29} \mathrm{FO}_{9}$} & Molecular weight $(<500 \mathrm{~g} / \mathrm{mol})$ & $392.46 \mathrm{~g} / \mathrm{mol}$ \\
\hline & & & & $\log \mathrm{P}(<5)$ & 2.29 \\
\hline & & & & H-Bond donor $(<5)$ & 3 \\
\hline & & & & H-Bond acceptor $(<10)$ & 6 \\
\hline & & & & Violation & 0 \\
\hline \multirow[t]{5}{*}{3} & \multirow[t]{5}{*}{ Remdesivir } & & \multirow[t]{5}{*}{$\mathrm{C}_{22} \mathrm{H}_{29} \mathrm{FO}_{9}$} & Molecular weight (<500 g/mol) & $602.58 \mathrm{~g} / \mathrm{mol}$ \\
\hline & & & & $\log \mathrm{P}(<5)$ & 3.40 \\
\hline & & & & H-Bond donor $(<5)$ & 4 \\
\hline & & & & H-Bond acceptor $(<10)$ & 12 \\
\hline & & & & Violation & 2 \\
\hline
\end{tabular}


4 Hydroxychloroquine

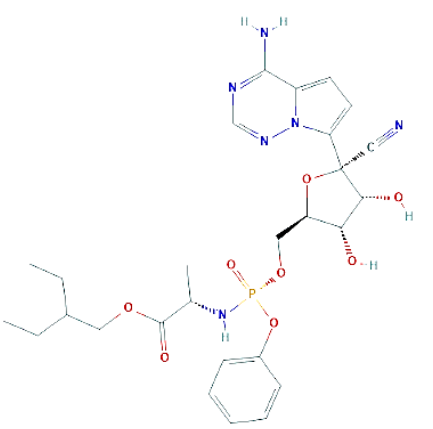

$5 \quad$ Azithromycin

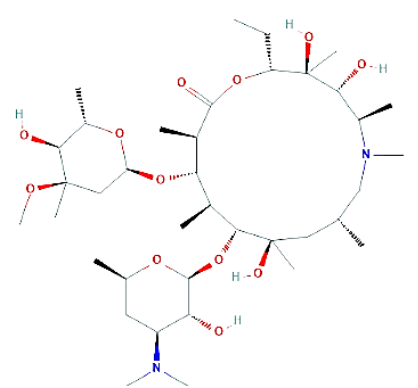

$\mathrm{C}_{18} \mathrm{H}_{26} \mathrm{CIN}_{3} \mathrm{O} \quad$ Molecular weight $(<500 \mathrm{~g} / \mathrm{mol})$

$$
\log \mathrm{P}(<5)
$$

H-Bond donor $(<5)$

H-Bond acceptor $(<10)$

Violation

$\mathrm{C}_{38} \mathrm{H}_{72} \mathrm{~N}_{2} \mathrm{O}_{12} \quad$ Molecular weight ( $\left.<500 \mathrm{~g} / \mathrm{mol}\right)$

$\log \mathrm{P}(<5)$

H-Bond donor $(<5)$

H-Bond acceptor $(<10)$

Violation
$335.9 \mathrm{~g} / \mathrm{mol}$

3.58

2

3

0

$749 \mathrm{~g} / \mathrm{mol}$

4.86

5

14

2 


\subsection{Drug-receptor binding energy and active site interaction}

All parameters were analysed to give an overview of comparative drug potency. Detailed results of drug binding energy are shown in Table 2. Lowest and mean binding energies were evaluated for comparing both natural bioactive compound and synthetic drug against $\mathrm{M}^{\text {pro }}$ of 6LU7. The lowest binding energy for liquiritin, dexamethasone, remdesivir, hydroxychloroquine and azithromycin were evaluated as -6.62, -7.11, -5.66, -6.46, -7.06 $\mathrm{kcal} / \mathrm{mol}$, while mean binding energies were found as $-6.62,-7.05,-5.66,-5.98,-6.59$ $\mathrm{kcal} / \mathrm{mol}$, respectively. Liquiritin showed binding formation with six active residues viz. THR26, GLY143, CYS145, HIS 164, GLU166 and GLN189 (Fig. 3E). Of which, four residues were similar to dexamethasone viz. THR26, GLY143, CYS145, and GLU166 (Fig. 2E). Three residues were identical with remdesivir viz. CYS145, GLU166 and GLN189 (Fig. 1D). Four residues were similar with hydroxychloroquine viz. GLY143, CYS145, HIS 164 (Fig. 1B) and GLN189 while two residues were similar in azithromycin viz. GLU166 and GLN189 (Fig. 1C). Naturally active compound liquiritin showed presence of conventional hydrogen bond with THR26, GLY143 (Fig. 3C), and GLU166. Moreover, $\pi-\sigma$ bond was observed in GLN189 residue. Carbon hydrogen-bond was resulted in-between CYS145 and HIS164 residues. Liquritin also possesses hydrophobic (Fig. 3D) and electrostatic interaction. Dexamethasone possessed five active residues viz. THR26, GLY143, CYS145, HIS163 and GLU166 (Fig. 2E). Of which, three active residues viz. THR26, GLY143 and GLU166 showed conventional hydrogen bonds (Fig. 2C), which were similar to natural compound liquiritin (Fig.3E). While in remdesivir and azithromycin, three and four active residues, respectively, have shown conventional hydrogen bond interactions and of which, one residue GLU166 was similar with liquiritin. Hydroxychloroquine possessed three active residues and showed presence of conventional hydrogen bond. Of which, GLY143 showed similar conventional hydrogen bond as in liquiritin. Furthermore, it also has similar kind of $\pi-\sigma$ bond interaction with GLN189 as found in liquiritin. 

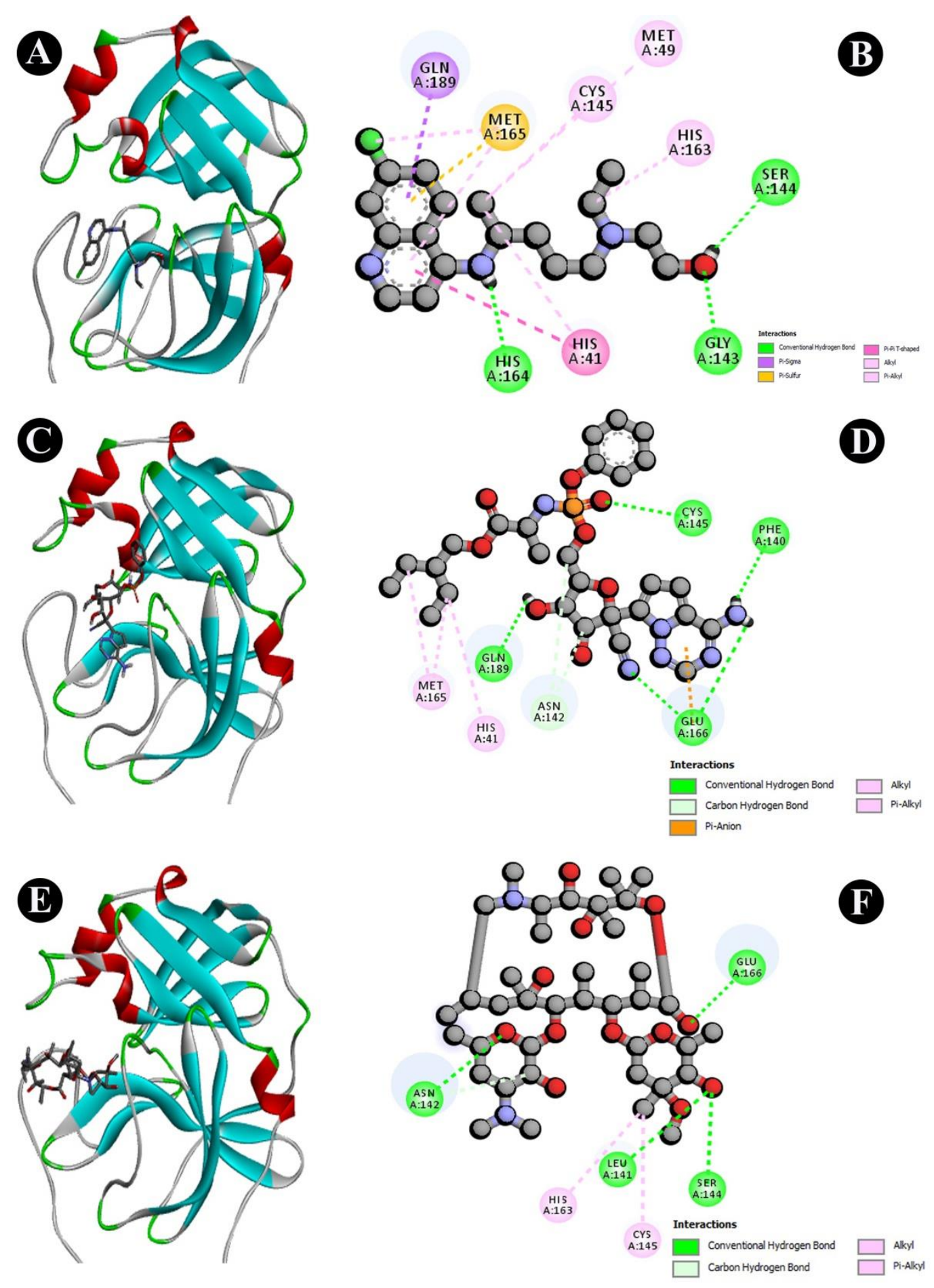

Fig. 1 Docking analysis of SARS-CoV-2 $\mathrm{M}^{\text {pro }}$ binding with Hydrochloroquine, Remdesivir and Azithromycin (A) 3D representation of Hydrochloroquine-SARS-CoV-2 $\mathrm{M}^{\text {pro }}$ interaction (B) $2 \mathrm{D}$ representation of Hydrochloroquine in active site of SARS-CoV-2 $\mathrm{M}^{\text {pro }}$ (C) 3D representation of Remdesivir-SARS-CoV-2 $\mathrm{M}^{\text {pro }}$ interaction (D) $2 \mathrm{D}$ representation of Remdesivir in active site of SARS-CoV-2 $\mathrm{M}^{\text {pro }}$ (E) 3D representation of AzithromycinSARS-CoV-2 $\mathrm{M}^{\text {pro }}$ interaction (F) 2D representation of Azithromycin in active site of SARSCoV-2 $\mathrm{M}^{\text {pro }}$ 


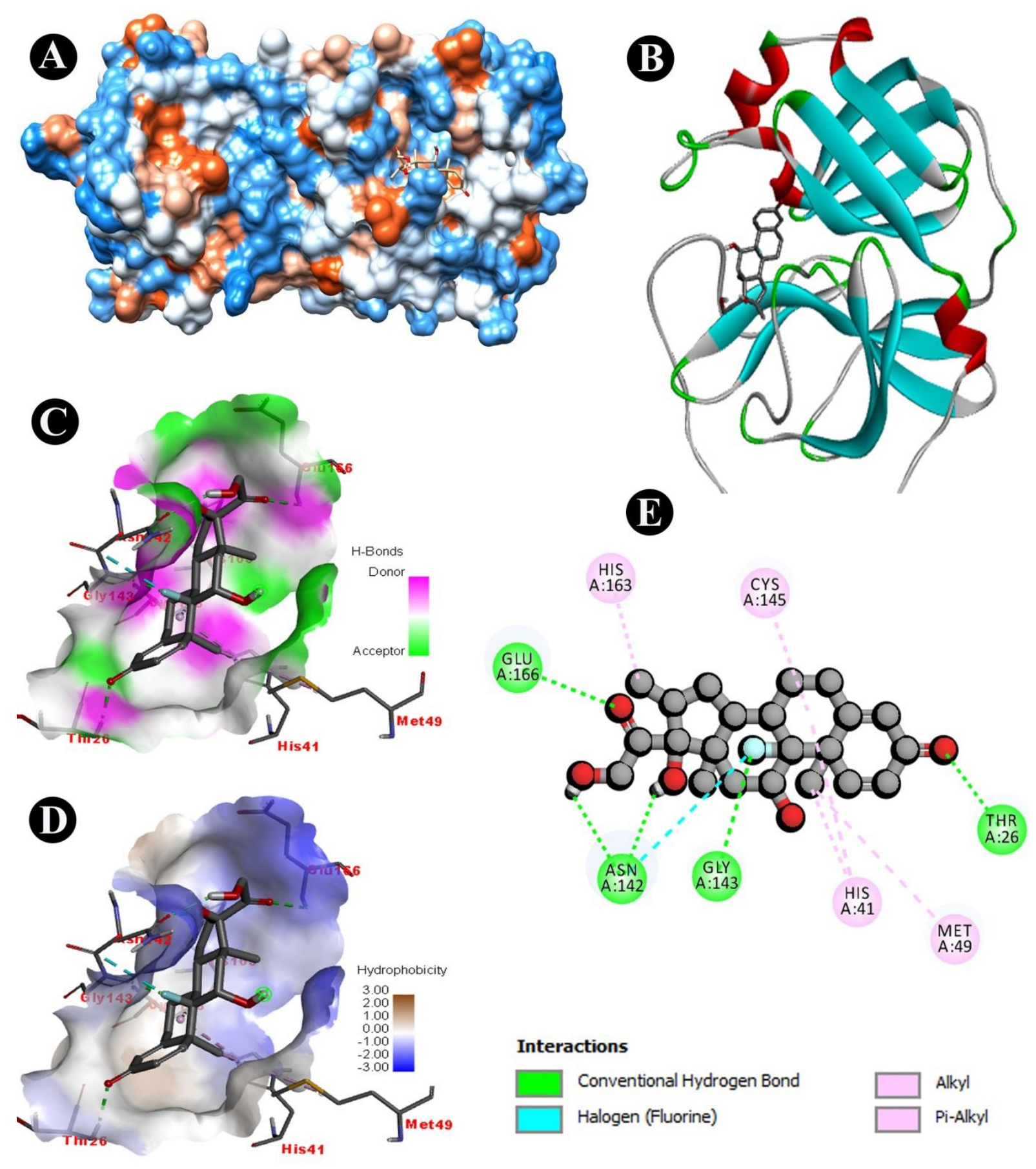

Fig. 2 Docking analysis of SARS-CoV-2 $\mathrm{M}^{\text {pro }}$ binding with Dexomethasone (A) hydrophobicity surface 3D representation (B) 3D representation of Dexomethasone -SARSCoV-2 $\mathrm{M}^{\text {pro }}$ interaction (C) Interactions of Dexomethasone through $\mathrm{H}$-bond in a pocket site of SARS-CoV-2 $\mathrm{M}^{\text {pro }}$ (D) InteractionsofDexomethasone through hydrophobic bond in a pocket site of SARS-CoV-2 $\mathrm{M}^{\text {pro }}$ (E) 2D representation of Dexomethasone in active site of SARS-CoV-2 $\mathrm{M}^{\text {pro }}$ 

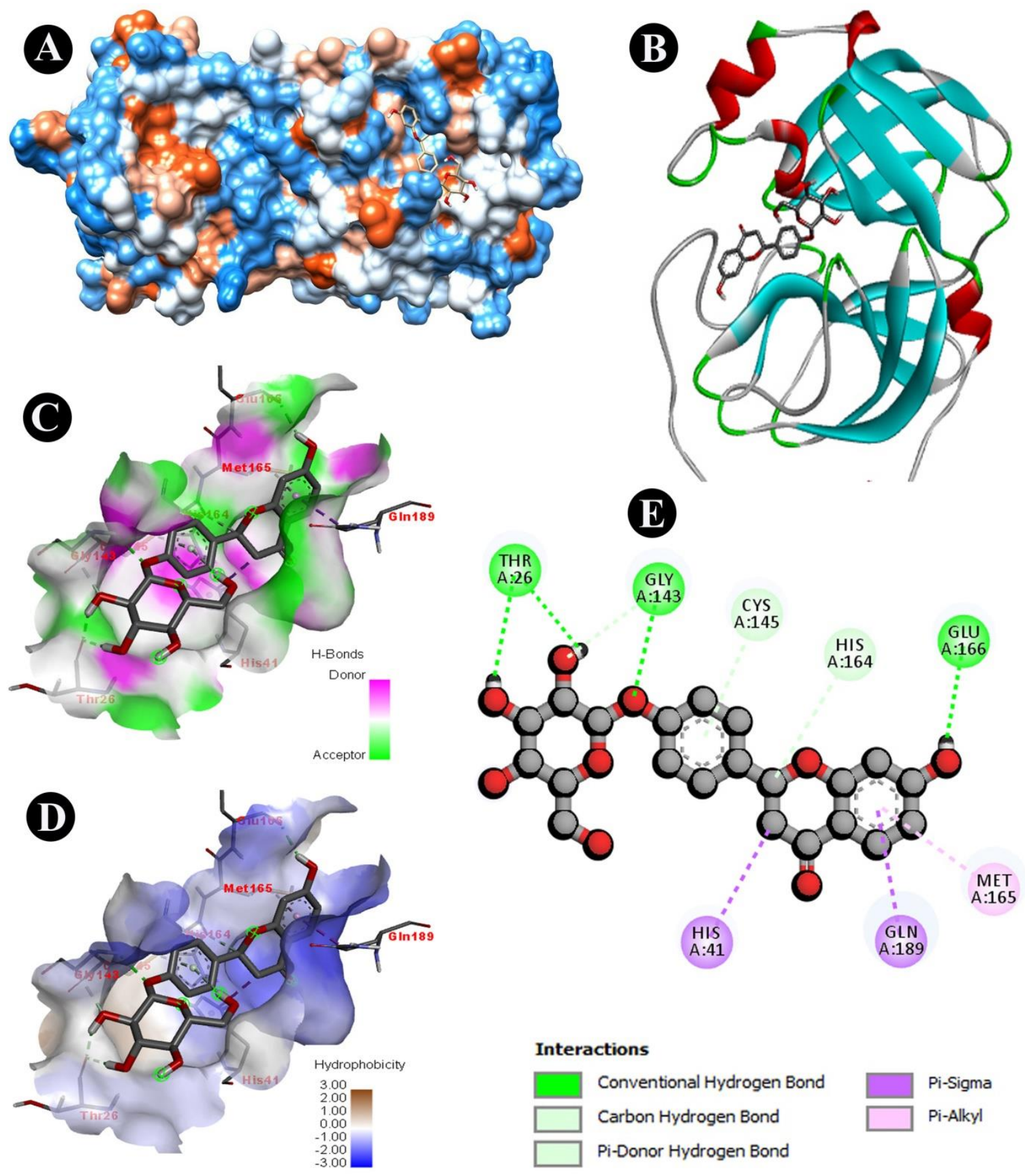

Fig. 3 Docking analysis of SARS-CoV-2 $\mathrm{M}^{\text {pro }}$ binding with Liquiritin (A) hydrophobicity surface 3D representation (B) 3D representation of Liquiritin-SARS-CoV-2 $\mathrm{M}^{\text {pro }}$ interaction (C) Interactions of Liquiritinthrough $\mathrm{H}$-bond in a pocket site of SARS-CoV-2 $\mathrm{M}^{\text {pro }}$ (D) Interactions of Liquiritin through hydrophobic bond in a pocket site of SARS-CoV-2 $\mathrm{M}^{\text {pro }}(\mathrm{E})$ $2 \mathrm{D}$ representation of Liquiritin in active site of SARS-CoV-2 $\mathrm{M}^{\text {pro }}$ 
Table 2. Binding energy, active site properties of all five drugs against SARS-CoV-2.

\begin{tabular}{clccl}
\hline Sr. No. & Name of compound & $\begin{array}{c}\text { Lowest Binding energy } \\
\mathbf{k c a l} / \mathbf{m o l}\end{array}$ & $\begin{array}{c}\text { Mean binding energy kcal/mol } \\
\text { Amino acid binding sites }\end{array}$ & \\
\hline $\mathbf{1}$ & Liquiritin & -6.62 & -6.62 & THR26, GLY143, CYS145, HIS164, \\
& & & & GLU166, GLN189 \\
$\mathbf{2}$ & Dexamethasone & -7.11 & -7.05 & THR26, GLY143, CYS145, HIS163, \\
& & & -5.66 & GLU166 \\
$\mathbf{3}$ & Remdesivir & -5.66 & -5.98 & PHE140, CYS145, GLU166, GLN189 \\
$\mathbf{4}$ & Hydroxychloroquine & -6.46 & & GLN189, CYS145, HIS163, HIS164, \\
& & & -6.59 & CYS145, HIS163, GLU166 \\
\hline
\end{tabular}




\subsection{Pharmacokinetic predictive studies}

The results of absorption, distribution, metabolism, excretion, and toxicity (ADMET) studies are shown in Table 3. Based on distribution data, CNS permeability logPS of liquiritin has shown similar result to dexamethasone. Liquiritin does not show cytochrome (CYP) metabolism and have better renal clearance. Furthermore, liquiritin and dexamethasone does not predict hepatotoxicity and skin sensitisation. Thus results of ADMET study have supported drug ability similarities of liquiritin and synthetic drug dexamethasone.

Table 3. ADMET prediction of the Liquiritn, Dexamethasone and Remdesivir.

\begin{tabular}{|c|c|c|c|}
\hline & Liquiritin & Dexamethasone & Remdesivir \\
\hline \multicolumn{4}{|l|}{ Absorption } \\
\hline Water solubility $(\log \mathrm{mol} / \mathrm{L})$ & -3.354 & -4.147 & -3.07 \\
\hline $\mathrm{CaCO}_{2}$ permeability (log Papp in $10^{-6} \mathrm{~cm} / \mathrm{s}$ & 0.507 & 0.793 & 0.635 \\
\hline Intestinal absorption (\% absorbed) & 46.076 & 81.31 & 71.109 \\
\hline Skin permeability (log Kp) & -2.736 & -3.972 & -2.735 \\
\hline P-glycoprotein substrate & Yes & Yes & Yes \\
\hline P-glycoprotein I inhibitor & No & No & Yes \\
\hline P-glycoprotein II inhibitor & No & No & No \\
\hline \multicolumn{4}{|l|}{ Distribution } \\
\hline VDss (human) (log L/kg) & -0.162 & -0.078 & 0.307 \\
\hline Fraction unbound (human) $(\mathrm{Fu})$ & 0.136 & 0.381 & 0.005 \\
\hline BBB permeability $(\log B B)$ & -1.146 & -0.695 & -2.056 \\
\hline CNS permeability (logPS) & -3.866 & -3.424 & -4.675 \\
\hline \multicolumn{4}{|l|}{ Metabolism } \\
\hline CYP2D6 substrate & No & No & No \\
\hline CYP3A4 substrate & No & No & Yes \\
\hline CYP1A2 inhibitor & No & No & No \\
\hline CYP2C9 inhibitor & No & No & No \\
\hline CYP2D6 inhibitor & No & No & No \\
\hline CYP3A4 inhibitor & No & No & No \\
\hline \multicolumn{4}{|l|}{ Excretion } \\
\hline Total clearance $(\log \mathrm{ml} / \mathrm{min} / \mathrm{kg})$ & 0.342 & 0.658 & 0.198 \\
\hline Renal OCT2 substrate & No & No & No \\
\hline
\end{tabular}




\begin{tabular}{|c|c|c|c|}
\hline \multicolumn{4}{|l|}{ Toxicity } \\
\hline $\begin{array}{l}\text { Max. tolerated dose (human) (log } \\
\mathrm{mg} / \mathrm{kg} / \text { day) }\end{array}$ & 0.186 & 0.097 & 0.15 \\
\hline hERG I inhibitor & No & No & No \\
\hline hERG II inhibitor & No & No & Yes \\
\hline Oral Rat Acute Toxicity (LD50) (mol/kg) & 2.553 & 2.504 & 2.043 \\
\hline $\begin{array}{l}\text { Oral Rat Chronic Toxicity (LOAEL) (log } \\
\mathrm{mg} / \mathrm{kg} \text { bw/day }\end{array}$ & 3.76 & 2.541 & 1.639 \\
\hline Hepatotoxicity & No & No & Yes \\
\hline Skin Sensitization & No & No & No \\
\hline Tetrahymenapyriformis toxicity $(\mu \mathrm{g} / \mathrm{L})$ & 0.285 & 0.299 & 0.285 \\
\hline Minnow toxicity (mM) & 4.089 & 2.535 & 0.291 \\
\hline
\end{tabular}

\section{Discussion}

COVID-19 is an infectious disease, caused by SARS-CoV-2 firstly identified in Wuhan, China, during December 2019 and still continuously spreading all over world, causing major outbreak to health sector. Therefore, there is an urgent need to develop vaccines or novel drugs to manage current pandemic situation. Novel drug development has required more time and consumption of more time cannot be affordable for such a contagious disease, in present scenario. In this context, pre-existing natural phytoconstituents have played a vital role as they possess disease resistant activity naturally. Rhizome and root were used as oral medicine to treat various diseases such as lung ailment, cough, tuberculosis, gastric ulcer, diabetes, kidney stone and stomach ache (35). Analysis of naturally active compound based on virtual screening is one of the footsteps of novel drug development. Present study reveals the inhibitory activity of natural compound liquiritin against 6LU7 crystallographic structure of SARS-CoV-2 $\mathbf{M}^{\text {pro }}$ which has similarities with synthetic drug dexamethasone with an additional binding off our residues i.e. THR26, GLY143, CYS145, and GLU166 in active site. Of which three residues, have similar hydrogen bond interactions as with liquiritin. Moreover, presented bioactive compound shows similar results of distribution data, CNS permeability $\log$ PS with dexamethasone. Therefore, present investigation gives basis for further validation of drug using in-vitro and in-vivo studies which can be effective drug against COVID-19. 


\section{Conclusion}

Presently, COVID-19 infection increasing globally, It is mainly because of high rate of spreading capacity and infectious properties. Therefore, it is prerequisite to the scientific community to develop naturally derived drugs which has capabilities to stop the replication of the virus within the host cell without any side effect. Present paper also supportive preexisted natural therapy which can be more beneficial and accountable to manage current pandemic situations. The present investigation gives insight of a natural drug liquiritin from Glycirrhyza glabra, which shows potential drug receptor interaction through in-silico analysis. In earlier studies it is already reported that liquiritin has certain promising anti-viral and anti-inflammatory activities. Therefore, we recommend liquiritin can be a potential candidate to counter COVID-19 infection. Though in-vitro and in-vivo clinical trials furtherly needed to understand the interactive properties toxicity and mortality rates. With our best knowledge we represent that liquiritin is one of the potential inhibitor for SARS-CoV-2 infection.

\section{References}

1. WHO. 2020a. https://covid19.who.int/table (accessed July 7, 2020).

2. Holshue ML, DeBolt C, Lindquist S, Lofy KH, Wiesman J, Bruce H, et al. First case of 2019 novel coronavirus in the United States. N Engl J Med. 2020;

3. Bhatraju PK, Ghassemieh BJ, Nichols M, Kim R, Jerome KR, Nalla AK, et al. Covid19 in critically ill patients in the Seattle region-case series. N Engl J Med. 2020;382(21):2012-22.

4. Grein J, Ohmagari N, Shin D, Diaz G, Asperges E, Castagna A, et al. Compassionate use of remdesivir for patients with severe Covid-19. N Engl J Med. 2020;382(24):2327-36.

5. WHO. 2020b. https://www.who.int/emergencies/diseases/novel-coronavirus2019/advice-for-public/myth (Accessed July 7, 2020).

6. WHO. 2020c. https://www.who.int/emergencies/diseases/novel-coronavirus2019/question-and-answers-hub/q-a-detail/q-a-dexamethasone-and-covid-19 (Accessed July 7, 2020). 
7. Rosenberg ES, Dufort EM, Udo T, Wilberschied LA, Kumar J, Tesoriero J, et al. Association of treatment with hydroxychloroquine or azithromycin with in-hospital mortality in patients with COVID-19 in New York State. Jama. 2020;323(24):2493502.

8. Patel R, Vanzara A, Patel N, Vasava A, Patil S, Rajput K. Discovery of fungal metabolites bergenin, quercitrin and dihydroartemisinin as potential inhibitors against main protease of SARS-CoV-2. Prepr ChemRxiv. 2020.

9. Rastogi S, Pandey DN, Singh RH. COVID-19 pandemic: A pragmatic plan for ayurveda intervention. J Ayurveda Integr Med. 2020.

10. Salzberger B, Glück T, Ehrenstein B. Successful containment of COVID-19: the WHO-Report on the COVID-19 outbreak in China. Springer; 2020.

11. Ren J, Zhang A-H, Wang X-J. Traditional Chinese medicine for COVID-19 treatment. Pharmacol Res. 2020;155:104743.

12. National health commission of the people's republic of China. Guideline on diagnosis and treatment of covid-19 (trial 6th edition). 2020. http://www.nhc.gov.cn/xcs/zhengcwj/202002/8334a8326dd94d329df351d7 da8aefc2.Shtml (Accessed July 14, 2020).

13. Sedighinia F, Afshar AS. Antibacterial activity of Glycyrrhiza glabra against oral pathogens: an in vitro study. Avicenna J phytomedicine. 2012;2(3):118.

14. Dafni A, Yaniv Z, Palevitch D. Ethnobotanical survey of medicinal plants in northern Israel. J Ethnopharmacol. 1984;10(3):295-310.

15. Arseculeratne SN, Gunatilaka AAL, Panabokke RG. Studies on medicinal plants of Sri Lanka. Part 14: toxicity of some traditional medicinal herbs. J Ethnopharmacol. 1985;13(3):323-35.

16. Kumar A, Dora J. Review on Glycyrrhiza glabra: licorice. J Pharm Sci Innov. 2012;1(2):1-4.

17. Sabahi M, Mansouri SH, Ramezanian M, Gholam-Hoseinian A. Screening of plants from the southeast of Iran for antimicrobial activity. Int J Crude Drug Res. 1987;25(2):72-6. 
18. Yu Z, Ohtaki Y, Kai K, Sasano T, Shimauchi H, Yokochi T, et al. Critical roles of platelets in lipopolysaccharide-induced lethality: effects of glycyrrhizin and possible strategy for acute respiratory distress syndrome. Int Immunopharmacol. 2005;5(3):571-80.

19. Shah SL, Wahid F, Khan N, Farooq U, Shah AJ, Tareen S, et al. Inhibitory effects of Glycyrrhiza glabra and its major constituent glycyrrhizin on inflammation-associated corneal neovascularization. Evidence-Based Complement Altern Med. 2018.

20. Alwan AM, Nesrullah Z, Faraj E. Study the effect of ethanolic extract of Glycyrrhiza glabra on pathogenic bacteria. Int J Curr Microbiol Appl Sci. 2015;4(5):473-84.

21. Biondi DM, Rocco C, Ruberto G. Dihydrostilbene derivatives from Glycyrrhiza g labra leaves. J Nat Prod. 2005;68(7):1099-102.

22. Chemical Entities of Biological Interest.(ChEBI) CE of BI. http://www.ebi.ac.uk/chebi/searchId.do?chebiId=CHEBI:80845 (Accessed August 8, 2020).

23. Whorwood CB, Sheppard MC, Stewart PM. Licorice inhibits 11 beta-hydroxysteroid dehydrogenase messenger ribonucleic acid levels and potentiates glucocorticoid hormone action. Endocrinology. 1993;132(6):2287-92.

24. Sun Y-X, Tang Y, Wu A-L, Liu T, Dai X-L, Zheng Q-S, et al. Neuroprotective effect of liquiritin against focal cerebral ischemia/reperfusion in mice via its antioxidant and antiapoptosis properties. J Asian Nat Prod Res. 2010;12(12):1051-60.

25. Zhu J, Deng Y-Q, Wang X, Li X-F, Zhang N-N, Liu Z, et al. An artificial intelligence system reveals liquiritin inhibits SARS-CoV-2 by mimicking type I interferon. bioRxiv. 2020.

26. Jin Z, Du X, Xu Y, Deng Y, Liu M, Zhao Y, et al. Structure of M pro from SARSCoV-2 and discovery of its inhibitors. Nature. 2020;1-5.

27. Lipinski CA, Lombardo F, Dominy BW, Feeney PJ. Experimental and computational approaches to estimate solubility and permeability in drug discovery and development settings. Adv Drug Deliv Rev. 1997;23(1-3):3-25.

28. SWISSADME. http://www.swissadme.ch/ (Accessed August 8, 2020). 
29. Andrade B, Ghosh P, Barth D, Tiwari S, Santana RJ, Silva WR de AS, et al. Computational screening for potential drug candidates against SARS-CoV-2 main protease. 2020.

30. Wang M, Cao R, Zhang L, Yang X, Liu J, Xu M, et al. Remdesivir and chloroquine effectively inhibit the recently emerged novel coronavirus (2019-nCoV) in vitro. Cell Res. 2020;30(3):269-71.

31. Zhang L, Lin D, Sun X, Curth U, Drosten C, Sauerhering L, et al. Crystal structure of SARS-CoV-2 main protease provides a basis for design of improved $\alpha$-ketoamide inhibitors. Science (80- ). 2020;368(6489):409-12.

32. Morris GM, Huey R, Lindstrom W, Sanner MF, Belew RK, Goodsell DS, et al. AutoDock4 and AutoDockTools4: Automated docking with selective receptor flexibility. J Comput Chem. 2009;30(16):2785-91.

33. Schrödinger. The PyMOL Molecular Graphics System, Version 2.3. 2020.

34. Pires DE V, Blundell TL, Ascher DB. pkCSM: predicting small-molecule pharmacokinetic and toxicity properties using graph-based signatures. J Med Chem. 2015;58(9):4066-72.

35. Asl MN, Hosseinzadeh H. Review of pharmacological effects of Glycyrrhiza sp. and its bioactive compounds. Phyther Res An Int J Devoted to Pharmacol Toxicol Eval Nat Prod Deriv. 2008;22(6):709-24. 